http://jmscr.igmpublication.org/home/

ISSN (e)-2347-176x ISSN (p) 2455-0450

crossref DOI: https://dx.doi.org/10.18535/jmscr/v9i3.12

\author{
Journal Of Medical Science And Clinical Research \\ IGM Publication \\ An Official Publication of IGM Publication
}

\title{
A Study on Complications in Spondylolisthesis Surgery
}

\section{Author \\ Dr Rahmat Ali (Ms (ortho), MCh (ortho) ) \& Fellowship in Spine', Dr Imran Akhtar M.S (Ortho) ${ }^{2^{*}}$}

${ }^{1}$ Professor and H.O.D (Ortho department), Maharishi Vashishtha Autonomous State Medical College, Basti, UP, India

${ }^{2}$ Sr. Orthopaedic Surgeon

*Corresponding Author

Dr Imran Akhtar M.S (Ortho)

Sr. Orthopaedic Surgeon

\begin{abstract}
Spondylolisthesis is a common pathological condition caused due to various causes in young and old persons. The forward slippage of one vertebra over the other alters the bio-mechanics to an extent that can result in various postoperative complications. The most common complications reported are neurogical deficits, pseudoarthrosis. Similarly, neurogical complications are a common occurrence postoperatively in the treatment of high grade slips. Percentage of reduction of slips, slips angle. and traction injury to nerve root tend to have a complex interaction leading to neurogical injuries. Finally Minimally invasive Spine Surgery (MISS) are now being used to treat Spondylolisthesis.

Keywords: Transitional syndrome, neurological complications, pseudoarthrosis, Spondylolisthesis, complications.
\end{abstract}

\section{Introduction}

Spondylolisthesis is a common pathological condition caused due to various causes in young and old persons. It may be due to defects in pars, degenerative, traumatic or pathological issue or a tendency of slippage of one vertebra over other. This may be asymptomatic or symptomatic causing mechanical back pain and/or neurological compression. Surgerical intervention with reduction of slip, correction of deformity along with decompression and fusion form the standard of care when conservative treatment fails. The incidence of complications depends upon numerous factors like the pathology of Spondylolisthesis it's grade. Type of fusion and bone graft id used .

\section{Various Complications}

\section{Transition syndrome}

Every technique of spine surgery has its advantages and disadvantages. For example- when a fusion surgery is done, there are chances of pseudolarthrosis. It has been postulated that a solid fusion increase the stresses on adjacent segments which may cause spondylolishthesis acquista or transition syndrome. in young patients with pars defect and no-slip or disc degeneration, pars repair should ideally be performed. This is thought a preserve the motion segment and thus adjancentsegment stresses. Early results showed clinical improvement. Strict care as to not damage the adjacent facet capsule during pedicle instrumentation is recommended as this has been 
shown to increase adjacent segment motion. Restoration of mechanical alignment, Lumbar lordosis, slip angle and a reduction might go a long way to reduce stresses across the fused and adjacent segments.

\section{Minimally Invasive Spine Surgery (MISS)} Achieving optimum surgical outcome with minimum collateral damage forms the basis of MISS. The benefit of MISS like early ambulation, reduced blood loss, shorter length of hospital stay.Utility of MISS in spondylolisthesis surgery deserve special attention due to altered biomechanics. MISS has several advantage like preservation of posterior tension band, contralateral facet joint. A 4-year fellow-up study of 3 patients with low-grade spondylolisthesis operated with MIS TLIF showed $80 \%$ fusion rates and $8 \%$ without fusion. Thus, fusion remains the choice in most cases of spondylolisthesis.

\section{Pseudoarthrosis}

Pseudoarthrosis is one of the commonest complications of spondylolisthesis surgery. The reason for this are numerous, for example- isthmic spondylolistheis has higher incidence of pseudoarthrosis than its degenerative counterpart. In spondyloisthesis the slip of one vertebra over the other causes a drastic change in mechanics which ultimately affects the biology of the fusion.

\section{Neurological complications}

One of the most dreaded complications after spine surgery is neurological worsening or paralysis. the incidence of neurological issues after posterior lumbar decompression and instrumented fusion surgery in cases of spondyloilisthesis may be as high as $50 \%$, the incidence of neurological deficits over the years increased due to greater attempts at reduction by spine surgeons particularly with lytic spondylolisthesis. The L5 nerver root is also the most commonly affected in clinical practise. The greater slips with larger attempts of reduction might be one of the causes of increased neurological deficits in such cases. Reduction helps in indirect neural decompression restoration of sagital alignment, facilitates arthorodesis.
Frequently use neuromonitoring in cases of highgrade spondylolisthesis.

\section{Unusual and rare complications}

As mentioned above, one of the most common complications of spondylisthesis surgery is pseudoarthrosis. Though most of them are asymptomatic, some may cause gross biochemical failures. Failure of fusion may cause the failure of mechanicale constructs with loosening and breakage of screws, loss of reduction and migration of interbody cages with or without neurological compromise.

\section{Conclusion}

The biomechanics of spondylolisthesis are different from other lumbar degenerative pathologies. Complications like neurological deterioration, pseudoarthrosis, and transition syndromes may occur. Advances in modern medicine like interbody fusion techniques, neuromonitoring, and osteobiologics help to reduce their incidence.

\section{Reference}

1. Moller $\mathrm{H}$ Hedlund $\mathrm{R}$ Instrumented and noninstrumented posterolateral fusion in adult spondylolisthesis a prospective landomized study: Part 2. Spine (Phila Pa 1976) 2000;25:1716-21.

2. Longo UG Loppini M, Romeo G Maffulli $\mathrm{N}$, Denaro V. Evidence based surgical management of spondylolisthesis: Reduction or arthrodesis in situ. J Bone Joint Surg Am 2014;96:53-8.

3. Jones TR, Rao RD. Adult isthmic spondylolisthesis: Diagnosis and treatment. J Am Acad Orthop Surg 2009; 17:609-17.

4. Matsuaga S, S Sakou T, Morizono Y, Masuda A demirtas AM. Natural History of degenerative spondylolisthesis. Pathogenesis and natural course of the slippage. Spine (Phila $\mathrm{Pa}$ 1976) 1990:15:1204-10. 
5. Unnithan AKA. A brief review of literature of sponatenous spinal epidural hematoma in the context of an idiopathic spinal epidural hematoma. Egypt J Neurosurg 2019;34:21. doi:10.1186/s41984-019-0046-7

6. Baek BS. Hur JW, Kwon KY, Lee HK. Spontaneous spinal epidural hematoma. J Korean Neurosurg Soc 2008;44:4 0-2

7. Figueroa J De vine JG. Spontaneous spinal epidural hematoma: Litrature review. J Spine Surg 2017;3:58-63.

8. .Zuo B, Zhang $\mathrm{Y}$, Zhang $\mathrm{J}$, et al. Spontaneous spinal epidural hematoma: A case report. Case Rep Orthop Res 2018;1:26-33

9. Km EJ. Ahn J Kim SJ. Spontaneous spinal epidural hematoma of the thoracic spine after herbal medicine: A case report. BMC Complement Altern Med 2018;18:291

10. Garg B, Singla A, Batra S, Kumar S. Early migration of bone graft causing sigmoid colon perforation after trans-foaminal lumbar interbody fusion. J Clin orthop Trauma 2017:8:165-7.

11. Robert W gaines RW L5 vertebrectomy for surgical treatment of spondyloptosis: 30 Cases in 25Years. Spine (Philla $\mathrm{Pa}$ 1976) 2005:30(6supp)S66-70.

12. Kwon BK, Albert TJ. Adult low-grade acquired spondylolysis and spondylolisthesis. J Neuro Surg Spine. 2010:13:596-93.

13. LEE C, DORcil J, radomisli TE. Nonunion of spine. A review Clin Orthop 2004; 419; 17-5.

14. Mobbs RJ, Raley DA Complication with K-Wire insertion for percutaneous pedicle screws. J Spianl Disord Tech 2014;27;3904.

15. LEE ck, accelerated degeneration of the segement adjacent to a lumbar fusion. spine (Phila PA 1976) 1988 13:375-7. 